\title{
Ultrastructural studies on the corticating filament of Chara zeylanica
}

\author{
Swetha Balakrishnan*, Rani Govindarajan \\ Department of Plant Biology and Plant Biotechnology, S.D.N.B.Vaishnav College for Women, \\ Chennai - 600 044, Tamil Nadu, India \\ *Corresponding author, E-mail: swethabal@gmail.com
}

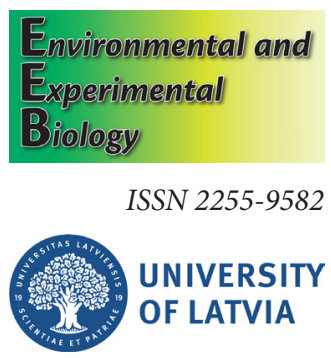

\begin{abstract}
The morphology of charophytes have developed curiosity in many researchers to fully understand their cell structure, physiology, biochemistry and phylogeny. In this regard, a number of studies on the ultrastructure of the internodal cell of corticate and ecorticate members of charophytes have been carried out. Although there are several studies on the internodal cells, there are no detailed investigations on the ultrastructure of corticating filaments of the genus Chara. Hence, this paper focuses on the ultrastructural study of the corticating filaments of Chara zeylanica, observed under transmission electron microscope, along with the ultrastructure of the internodal cell. The study revealed the presence of charosomes on the cell wall of the corticating cells along with other cell inclusions such as amitotic nucleus, chloroplast, mitochondria, glycosome, echinoid bodies, lipids, endoplasmic reticulum and crystalline inclusions.
\end{abstract}

Key words: Chara zeylanica, corticating filament, ultrastructure. Abbreviations: TEM, transmission electron microscopy.

\section{Introduction}

Charophytes are a group of green algae that colonized fresh waters 450 to 500 million years ago and gave rise to land plants, thus bringing a great transformation in the world of plants. This transformation and evolution can be further understood with molecular studies on Charophytes. Charophytes are not only important from evolutionary aspects related to formation of land plants, as they also changed the biochemistry and natural history of the planet. Many features of Charophytes are similar to modern land plants and hence are used as model organisms for the study of cell biology, development, physiology, and ecology of plants (Delwiche, Cooper 2015; Lemieux et al. 2016). Hence, there are extensive ultrastructural studies on charophytes that throw more light on the evolution of land plants (Pickett-Heaps, Marchant 1972; Pickett-Heaps 1975; Becker, Marin 2009; Harholt et al. 2016). Studies on the taxonomic and phylogenetic relationship of charophytes is further substantiated and redefined by molecular analysis of chloroplast and nuclear genomes and transcriptomes (Delwiche, Cooper 2015).

The order Charales includes a single family Characeae, which is comprised of five genera: Chara Linnaeus, Lamprothamnium J.Groves, Lychonothamnus (Ruprecht) A.Braun., Nitellopsis Hy., Nitella C.Agardh, and Tolypella (A.Braun) A.Braun. The genus Chara includes macroscopic green algae having a main axis differentiated into nodes and internodes (Pal et al. 1962). The filamentous stem of the plant and its branchlets are formed by large vacuolated internodal cells alternating with flat nodal cells. These internodal cells are surrounded by a layer of filamentous cortical cells. Each node bears a whorl of branchlets with nodes and internodes.

This is the only genus of the order Charales consisting of corticated members. Chara species with a corticating sheath are referred to as corticated species, e.g. Chara zeylanica, Chara globularis, Chara brachypus, and Chara vulgaris, and those that lack corticating sheath are referred to as ecorticated species e.g. Chara corallina, Chara braunii, and Chara succinata (Zaneveld 1940). While there are extensive ultrastructural studies on Chara (Crawley 1965; Pickett-Heaps 1967; Barton 1967; Franceschi, Lucas 1981; Lucas, Franceschi 1981; McLean, Juniper 1988; Cook et al. 1998; Stabenau et al. 2003), not much is known about the ultrastructure of the corticating threads surrounding the internodal cells of Chara.

The corticating sheath of charophytes is a key character in the identification of the species. The cortex may be haplo-, diplo- or triplostichous, based on the number of secondary filaments produced between two primary filaments of the corticating sheath (Wood, Imahori 1965). Also, the corticating filaments consist of nodes, which give rise to spine cells. Various characters of the spine cells also help in the identification of a species or sub-species. Further, the presence or absence of corticating cells in part or wholly in the branchlet is also a key character for determination of a species. As an example, in C. globularis the entire branchlet 
is corticated, while in C. zeylanica the basal segment of the branchlet alone is ecorticate (Zaneveld 1940). In Chara flaccida the main axis is corticated but the entire branchlet is ecorticate.

In an evolutionary aspect, the corticated species are considered to be less evolved than the ecorticate counterparts (Wood, Imahori 1965). Although the importance of the corticating sheath has been studied in terms of classification, its ultrastructure has not been observed in detail. This paper deals with the structural details of the corticating cells of C. zeylanica.

\section{Materials and methods}

Samples of Chara zeylanica were collected from a rain-fed lake in Vandalur, Kanchipuram district, Tamil Nadu, India. Samples were collected in the post-seasonal monsoon period in February, 2015 to 2018. Five mature samples in their vegetative phase were randomly selected from each collection for transmission electron microscopy (TEM) analysis.

Cytoplasmic movement taking place inside the cells was observed by mounting fresh growing tips that had not yet developed a corticating sheath, under a binocular microscope (Olympus $\mathrm{CH} 20 \mathrm{i}$ ) and photographed with a Sony Cybershot DSC-T77 10.1 MP digital camera. Similarly the arrangement of the chloroplast within the internodal cell was observed under a light microscope after removing the cortex of a young internodal cell with the help of a new razor blade. A cross section of the internodal cell was taken by hand section to observe the orientation of the cortex around the cell.

The actively growing tips and matured internodal cells of fresh C. zeylanica were fixed in $4 \%$ glutaraldehyde and post-fixed in $2 \%$ osmium tetroxide. The material was successively dehydrated in a series of progressively more concentrated rinses of acetone (20 to 100\%) and embedded in Spurr resin (Stabenau et al. 2003). Sections were taken using an Ulathrin diamond knife, contrasted with uranyl acetate, and observed using a transmission electron microscope Philips EM201C. A total of 25 sections were observed and the best were photographed. Measurements of each organelle with three observations for each organelle were recorded and their average and standard deviation were calculated.

\section{Results}

\section{Structure of the thallus}

Charophyte thallus was highly organized with an alternating arrangement of nodes and internodes. The main axis was of unlimited growth, anchored to the soil by means of filamentous rhizoids. Main axis was differentiated into nodes and internodes, with the internodes in some species being enveloped by a single-cell thick corticating sheath.
The corticating sheath also had a node and internode pattern, where the nodes gave rise to the spine cells. The node of the main axis gave rise up to $9-11$ filamentous branchlets, arranged in a whorl. Each branchlet consisted of nodes and internodes, with a corticating sheath. The nodes of the branchlet gave rise to the bracts, bracteoles and gametangia.

\section{Ultrastructure of corticating cells}

Thallus organization of Chara showed much complexity. In Chara the long internode forming the main stem was surrounded externally by a layer of cortical cells, which also divided during growth and produced spines (Fig. 1A). The layer of these filaments growing around the internodal cell gave a sheath-like appearance under a light microscope. The cortex of Chara was found encrusted with calcium and magnesium carbonate, especially in plants collected from hard water. The elongate cells are ensheathed around the axial internodal cell as the corticating layer. These corticating cells partly originated from the lower nodal cell as ascending filaments that grew upward, and partly from the upper nodal cell growing downward as descending filaments. The ascending filaments covered the lower half of the internodal cell and descending filaments covered the upper half of the internodal cell.

Ultrastructure of the corticated sheath of C. zeylanica revealed many features similar to the ultrastructural details of the internodal cell. In cross section of the internodal cell under a light microscope, the corticating threads showed calcification between the cell wall of the internodal cell and the cortex (Fig. 1B). Each cortex cell was surrounded by a typical fibrous cell wall. The single celled cortex filament, which varied in number from 30 to 32 , formed a sheath around the internodal cell. Since they were compressed into a sheath-like structure, the cells appeared to be interlocked with one another (Fig. 1C).

However, each cell was distinct and this was seen clearly in the cell wall region where the adjacent cortex cells overlapped each other (Fig.1D). The cell wall thickness in mature cells on the outer side measured $0.33 \mu \mathrm{m}$ and the thin wall on the inner side was $0.08 \mu \mathrm{m}$ in thicknress. The cell wall was differentiated into outer fibrillar, middle thin spongy and innermost fibrillar layers. Some of the cortex cells had a large central vacuole similar to a matured internodal cell and few of the cortex cells appeared with dense cytoplasm without a central vacuole or peripheral cytoplasm (Fig. 1E). Chloroplasts were found aligned as a chain along the periphery with multi-thylakoid lamellae organized into grana with starch grains and lipid bodies around it (Fig. 1D). Amitotic nuclei with nucleoli were also observed. Charosomes were observed along the periphery and development of charosome from the inner wall was also seen. Other cytoplasmic inclusions observed were echinoid bodies, glycosomes, endoplasmic reticulum, and mitochondria (Fig. 1E). 

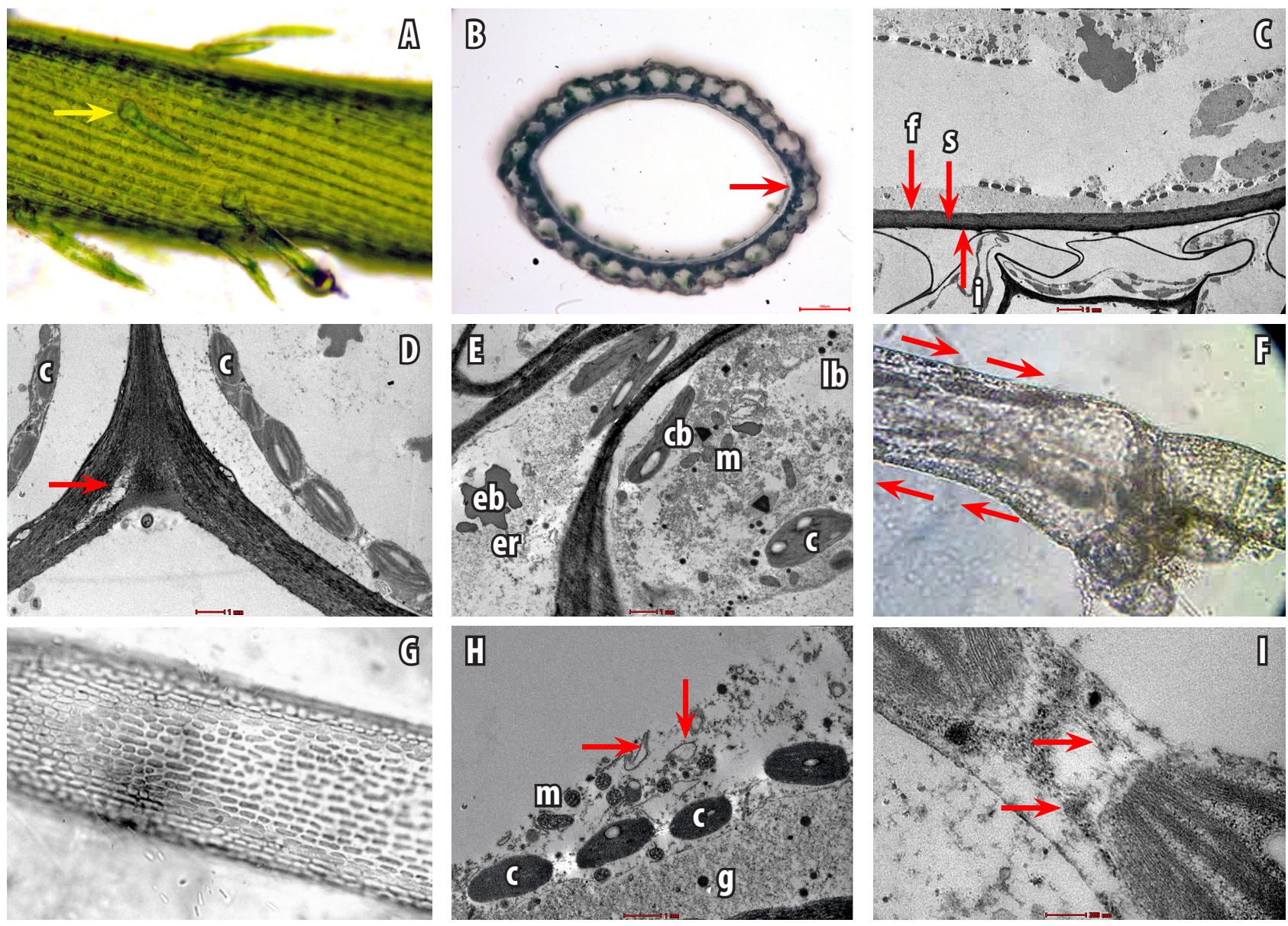

Fig. 1. Ultrastructure of Chara zeylanica cells. A, internodal cell with corticating filaments and spine cells (arrows). B, CS of internodal cell showing heavy calcification between the cell wall and corticating layer (arrows). C, cell wall of internode differentiated into outer fibrillar (f), middle spongy (s), inner fibrillar (i). Corticating cell with thick outer cell and thin inner cell wall closer to the cell wall of internodal cell. D, cell wall of two adjacent cortical cells showing charosome development. E, corticating cell with cell inclusions viz. chloroplast (c), lipid bodies (lb), endoplasmic reticulum (er), mitochondria (m), echinoid bodies (eb), and crystalline bodies (cb). F, Internodal cell under a light microscope showing cytoplasmic streaming (arrow). G, front view of an internodal cell showing uniform arrangement of chloroplast. $\mathrm{H}$, chain of chloroplasts in the internodal cell with mitochondria (m), glycosomes (g) and endoplasmic reticulum (black arrow heads). I, microfilaments (arrows) running parallel between adjacent chloroplast.

\section{Ultrastructure of the internodal cell}

The internodal cell was up to $7 \mathrm{~mm}$ in length and 515 $\mu \mathrm{m}$ in diameter. Under a light microscope it showed a large vacuole in the center and a thin layer of cytoplasm streaming around the vacuole (Fig. 1F), along with a chain of discoid chloroplasts moving in the upward direction on one side of the cell and the downward direction on the other side of the cell, thus exhibiting "cytoplasmic streaming movement". The front view of a light microscopic image of vegetative internodal cells showed a layer of uniformly aligned chloroplasts (Fig. 1G).

Ultrastructure of the internodal cell showed a thick stratified cell wall differentiated into the outer fibrillar layer, middle spongy layer and innermost fibrillar layer (Fig. 1C). Along the periphery of the cell in the cytoplasmic region, the chloroplasts were found aligned with their long axis parallel to the longitudinal axis of the cell arranged in a loose spiral pattern embedded in the cytoplasm (Fig.
$1 \mathrm{H})$. Chloroplasts with size $2.74 \pm 0.70 \mu \mathrm{m}$ in length and $1.03 \mu \mathrm{m}( \pm 0.08)$ in width lined the inner surface of the cell wall, showing multi-thylakoid lamellae organized into grana, starch grains and lipid bodies (Fig. 1H). Prominent starch grains were observed in chloroplasts of mature cells. Two successive chloroplasts were linked by microfilament bundles, which appeared to be bound to the surface of the chloroplast (Fig. 1I). In some of the chloroplasts, small vesicle-like structures budding from the margin of the plastid were observed (Fig. 2A). The nucleus measured $11.78 \pm 0.85 \mu \mathrm{m}$ in length and $6.33 \pm 0.71 \mu \mathrm{m}$ in width with a nucleoli and electron dense inclusions (Fig. 2B). Echinoid bodies had a central core and an outer thin electron dense layer (Fig. 2C). Mitochondria measuring $0.61 \pm 0.13 \mu \mathrm{m}$ in length and $0.36 \pm 0.03 \mu \mathrm{m}$ in width were numerous in some cells and limited in other cells. Mitochondria had a clear double membrane and cisternae (Fig. 1H). Charosomes were observed with a single outer membrane 

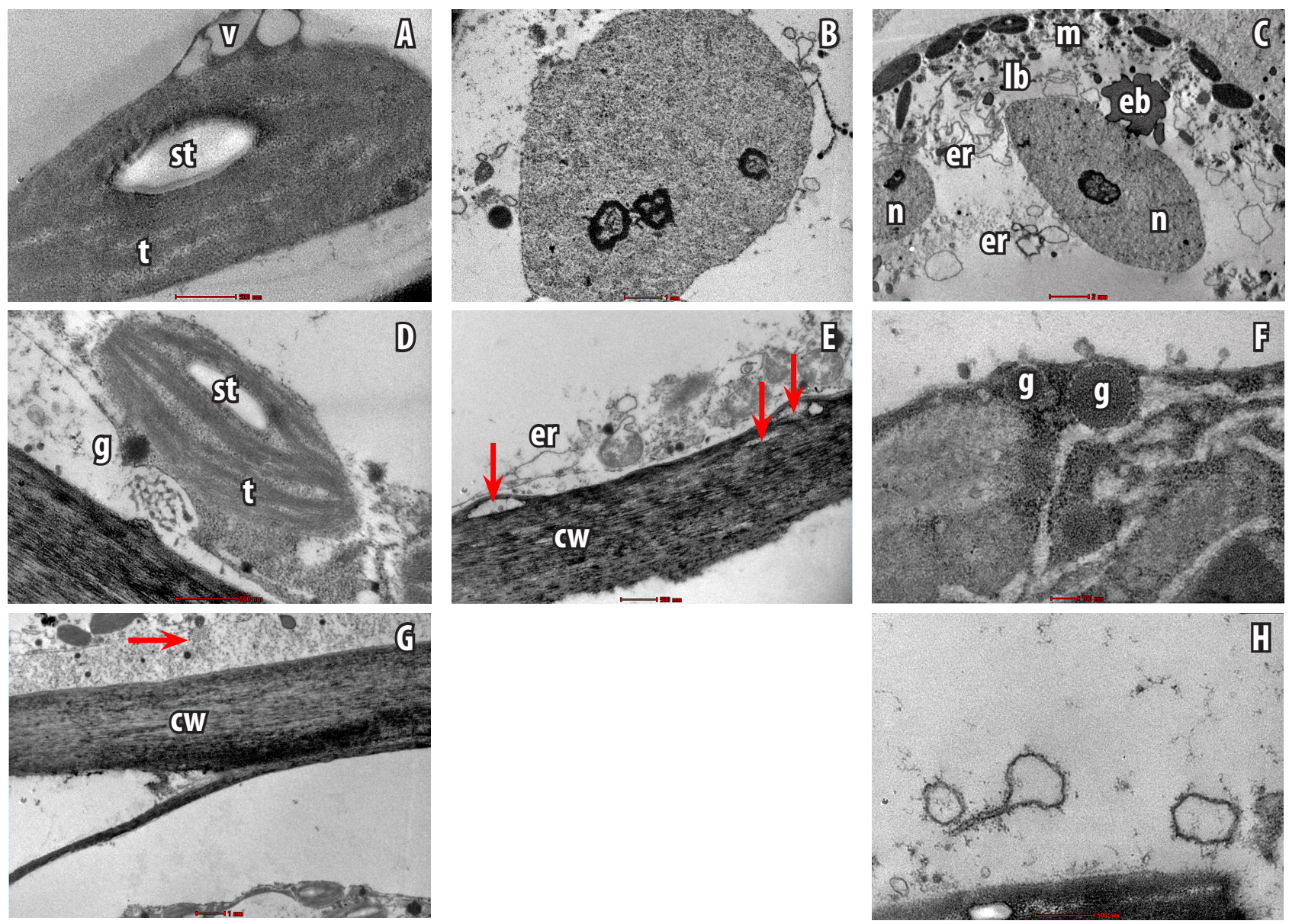

Fig. 2. Ultrastructure of Chara zeylanica cells. A, chloroplast with thylakoids (t), starch grains (st) and with vesicular structure (v). B, nucleus with nucleoli and electron dense inclusions. C, internodal cell with nucleus (n), echinoid body (eb), chloroplast (c), mitochondria (m), endoplasmic reticulum (er), glycosome (g) and lipid bodies (lb). D, matured charosome on the inner side of the cell wall with tubules. E, development of a charosome from the cell wall of an internodal cell. F, glycosome with wavy outer membrane and granular electron dense matrix. G, dictyosome (arrow) near the cell wall (cw, cell wall of corticating cell). $\mathrm{H}$, balloon like vesicle with a protuberance.

and numerous tubules (Fig. 2D). Charosomes were found to be developing from the invagination of plasmalemma and a number of vesicular bodies were observed near the charosome formation (Fig. 2E).

Large spherical homogenous lipid bodies without an outer membrane were found near chloroplasts. Glycosomes were observed as membrane-bound organelles with central granular matrix. Their outer membrane appeared to be thick with a wavy margin (Fig. 2F). Loosely packed bands of dictyosomes were also observed (Fig. 2G). Both beaded and smooth endoplasmic reticulum were found dispersed in the cytoplasm (Fig. 2B). A balloon shaped organelle with a protuberance was also observed in close relation with the microfilament and chloroplast (Fig. $2 \mathrm{H}$ ). The average measurements with standard deviation for all the organelles observed are provided in Table 1.

\section{Discussion}

In the early 1970s and 1980s ultrastructural studies concentrated much on charophytes and from 1990s till present, studies have been focused on molecular analysis of chloroplast and nuclear genomes to understand their phylogenetic relationship (Pickett-Heaps 1975; McLean, Juniper 1988; McCourt 1995; Karol et al. 2001). Due to its simple thallus where the internodal cells can be individually removed and the endoplasm and cell wall can be dissected and used for experimental manipulations, Chara and Nitella are used as model organisms to study cytoplasmic streaming (Pickett-Heaps, 1975). However, ultrastructural studies play a significant role in cellular research and for various biological investigations.

This study deals with the ultrastructure of the cortical cells of C. zeylanica. The arrangement of corticating filaments around the single celled internode in a compact manner was clearly observed by TEM (Fig. 1C). As the number of filaments is about 30 to 32 , they are compressed and appear to be interlocked with one another, although they are distinct. The cell wall appeared to be three layered with outer and inner fibrillar and middle spongy layers (Fig. $1 \mathrm{C}, 2 \mathrm{E})$. In certain areas, even the charosome developments were observed as seen in the internodal cells. Similar 
Table 2. Measurements of various organelles observed in the internodal and cortical cells of Chara zeylanica under transmission electron microscope

\begin{tabular}{lc}
\hline Organelle & Average $(\mu \mathrm{m})$ \\
\hline Width of cell wall & $3.33 \pm 0.00$ \\
\hline Length of nucleus & $11.78 \pm 0.85$ \\
\hline Width of nucleus & $6.33 \pm 0.71$ \\
\hline Length of chloroplast & $2.74 \pm 0.70$ \\
Width of chloroplast & $1.03 \pm 0.08$ \\
\hline Length of mitochondria & $0.61 \pm 0.13$ \\
Width of mitochondria & $0.36 \pm 0.03$ \\
\hline Length of echinoid body & $8.21 \pm 7.84$ \\
\hline Width of echinoid body & $5.10 \pm 2.81$ \\
\hline Glycosome & $0.26 \pm 0.03$ \\
\hline Lipid bodies & $0.25 \pm 0.03$ \\
Length of charosome & $0.53 \pm 0.16$ \\
Width of charosome & $0.35 \pm 0.22$ \\
Length of starch grains & $0.93 \pm 0.31$ \\
\hline Width of starch grains & $0.33 \pm 0.15$ \\
\hline Coated vesicle & $0.18 \pm 0.06$
\end{tabular}

observation of charosomes has been reported in C. corallina, C. braunii (ecorticate) and C. globularis (corticate) (Lucas, Franceschi 1981), but detailed study on the ultrastructure of the corticating filaments was not performed. Hence, our observations on detailed ultrastructure of the corticating filaments of C. zeylanica appears to be the first report.

Membrane-bound glycosomes, which have been studied in detail in C. corallina (Franceschi, Lucas 1981), were also clearly seen in C. zeylanica (Fig. 2F). The membrane of glycosomes was observed to be wavy in appearance with an electron-lucent space between the membrane and the central granular matrix, and more numerous glycosomes were observed in internodal cells than in the corticating filament (Franceschi, Lucas 1981). Among the algae, microbodies such as gycosomes, lipid bodies and spherical structures with crystalline inclusions were reported from Charophyceaen algae, such as Mougeotia, Spirogyra, Charales and a few non-charophycean algae (Stabenau et al. 2003). Microbodies with an amorphous or paracrystalline inclusion bounded by a single membrane were observed in Nitella sp. (Silverberg, Sawa 1973) and Chara fragilis (Stabenau et al., 2003). Chara is the only green algae with enzymes of the $\beta$-oxidation pathway located exclusively in peroxisomes. This is based on the observation of acetylCoA dehydrogenase, hydroxyacyl-CoA dehydrogenase and enoyl-CoA hydratase activity found in the microbodies of Chara cells (Stabenau et al. 2003).

Closely cell wall-associated charosomes were observed with tubules whose inner structure appeared to be continuous with the cell wall (Fig. 2D). These charosomes were reported as adifferent type of plasmalemma modification (Barton 1965; Lucas, Franceschi 1981). It was hypothesized that these tubules of charosomes increase the surface area of the cell wall, thus helping in transmembrane transport processes (Lucas, Franceschi 1981).

Charales is a group distinct from other charophycean orders as the species exclusively have organelles such as amitotic nuclei, echinoid bodies, glycosomes, chloroplast with granum, actin filaments and charosomes (Cáceres, Cocucci 1975; Pickett-Heaps 1975). Balloon like organelle with a single protuberance is observed in C. zeylanica (Nagai, Hayama 1979). Microbodies and lipid bodies are always found to be associated with chloroplasts (Silverberg, Sawa 1973). Microfilaments that were observed running parallel to the chloroplast (Fig. 1I) could represent actin filaments (Palevitz, Hepler 1975). Actin filaments are responsible for cytoplasmic streaming occurring in cells (Nagai, Hayama 1979).

The study of charophytes is still in its early stage, but further extensive research on the molecular phylogeny and taxonomy of the diverse taxa will encourage many more enthusiastic researchers to incorporate these algae in their research. To support this view, we performed molecular studies on C.zeylanica with partial sequencing of the plastidic $r b c L$ region to understand its phylogeny (Balakrishnan, Govindarajan 2019). Due to the fact that the variation in oospore character is not an environment-affected trait and represents only genetic variation (Casanova 1997), we also studied ultrastructure of the oospore by scanning electron microscopy in two different populations of C. zeylanica to evaluate if they represent different varieties of C. zeylanica (Balakrishnan, Govindarajan 2017). Therefore, the studies on Chara are very important, as it is also believed that the calcium carbonate deposition of Chara is a species-specific property (Apolinarska et al. 2011) and the systematic understanding of charophyte mineralization might throw some light in its significant role in phycoremediation of lakes.

\section{References}

Apolinarska K., Pelechaty M., Pukacz A. 2011. $\mathrm{CaCO}_{3}$ sedimentation by modern charophytes (Characeae): can calcified remains and carbonate $\delta^{13} \mathrm{C}$ and $\delta^{18} \mathrm{O}$ record the ecological state of lakes?-a review. Acta Limnol. Telmatol. 5: 55-66.

Balakrishnan S., Govindarajan R. 2017. Morphological and molecular analysis of two populations of Chara zeylanica Willd. Phykos 47: 1-7.

Balakrishnan S., Govindarajan R. 2019. New records of Chara zeylanica var. diaphana f. sundaralingii (Meyen) R.D.W. forma nova from South India with SEM studies on oospore and molecular studies ( $r b c L)$. Indian Hydrobiol. 18: 83-89.

Barton R. 1965. An unusual organelle in the peripheral cytoplasm of Chara cells. Nature 205: 201.

Barton R. 1967. Occurrence and structure of intranuclear crystals in Chara cells. Planta 77: 203-211.

Becker B., Marin B. 2009. Streptophyte algae and the origin of embryophytes. Ann. Bot. 103: 999-1004.

Caceres E.J., Cocucci A.E. 1975. Grains in Charophyta chloroplasts. 
Kürtziana 8: 142-143.

Casanova M.T. 1997. Oospore variation in three species of Chara (Charales, Chlorophyta). Phycologia 36: 274-280.

Cook M.E., Graham L.E., Lavin C.A. 1998. Cytokinensis and nodal anatomy in the charophycean green alga Chara zeylanica. Protoplasma 203: 65-74.

Crawley J.C.W. 1965. A cytoplasmic organelle associated with the cell walls of Chara and Nitella. Nature 205: 200-201.

Delwiche C.F., Cooper E.D. 2015. The evolutionary origin of a terrestrial flora. Curr. Biol. 25: 899-910.

Franceschi V.R., Lucas W.J. 1981. The glycosome of Chara: Ultrastructure, development, and composition. Ultrastruct. Res. 75: 218-228.

Harholt J., Moestrup O., Ulvskov P. 2016. Why plants were terrestrial from beginning. Trends Plant Sci. 21: 96-101.

Karol K.G., McCourt R.M., Cimino M.T., Delwiche C.F. 2001. The closest living relatives of land plants. Science 294: 2351-2353.

Lucas W.J., Franceschi V.R. 1981. Characean charosome-complex and plasmalemma vesicle development. Protoplasma 107: 255-267.

Lemieux C., Otis C., Turmel M. 2016. Comparative chloroplast genome analyses of streptophyte green algae uncover major structural alterations in the Klebsormidiophyceae, Coleochaetophyceae and Zygnematophyceae. Front. Plant Sci. 7: 697 .

McCourt R.M. 1995. Green algal phylogeny. Trends Ecol. Evol. 10:
159-163.

McLean B., Juniper B.E. 1988. Fine structure of Chara actin bundles, using rapid-freezing and deep-etching. Cell Biol. Int. Rep. 12: 509-517.

Nagai R., Hayama T. 1979. Ultrastructure of the endoplasmic factor responsible for cytoplasmic streaming in Chara internodal cells. J. Cell Sci. 36: 121-136.

Pal B.P., Kund B.C., Sundaralingam V.S., Venkataraman G.S. 1962. Charophyta. ICAR, New Delhi. 130 pp.

Palevitz B.A., Helper P.K. 1975. Identification of actin in situ at the ectoplasm-endoplasm interface of Nitella. J. Cell Biol. 65 : 29-38.

Pickett-Heaps J.D. 1967. Ultrastructure and differentiation in Chara sp. Austr. J. Biol. Sci. 20: 539-551.

Pickett-Heaps J.D., Marchant H.J. 1972. Phylogeny of the green algae: A new proposal. Cytobios 6: 255-264.

Pickett-Heaps J.D. 1975. Green Algae. Sinauer Associates, Stamford.

Silverberg B.A., Sawa T. 1973. An ultrastructural and cytochemical study of microbodies in the genus Nitella (Characeae). Can. J. Bot. 51: 2025-2032.

Stabenau H., Säftel W., Winkler U. 2003. Microbodies of the algae Chara. Physiol. Plant. 118: 16-20.

Wood R.D., Imahori K.A. 1965. A revision of the Characeae. Cramer, Weinheim. 904 pp.

Zaneveld J.S. 1940. The Charophyta of Malaysia and adjacent countries. Blumea 4: 1-223. 